supervision register could be said to be achieving its aims where this has occurred. Conversely, the resultant impact on staff time for additional meetings and administration was fairly small.

Finally, there is a need for greater training for keyworkers in risk management together with close supervision to ensure a good service to patients and to provide support to the staff.

\section{References}

CaldicotT, F. (1994) Supervision registers: the College's response. Psychiatric Bulletin, 18, 385-388.

HAGHIGHAT. R. (1994) Support registers instead of supervision registers (letter). Psychiatric Bulletin 18. 774

HARRISON, G. \& BARTLETT, P. (1994) Supervision registers for mentally ill people. British Medical Joumal, 309. 551552.
HoLLOWAY, F. (1994) Supervision registers: recent government policy and legislation. Psychiatric Bulletin. 18, 593-596.

MCCARTHY, A., Roy, D., Holloway, F. et al (1995) Supervision registers and the Care Programme Approach: a practical solution. Psychiatric Bulletin. 19, 195-199.

McEvoy, P. (1996) Supervision registers: implications for key workers. Mental Health Nursing. 16(4), 8-10.

GUinN, J. D. (1995). Supervision registers. Psychiatric Bulletin, 19, 513.

VAUGHAN, P. J. (1996). The supervision register: one year on. Psychiatric Bulletin. 20, 143-145.

Phillip J. Vaughan, Project Manager, Forensic Project Team, The Wessex Consortium, Highcroft, Romsey Road. Winchester, Hampshire SO22 5DH

\title{
Section 17 of the Mental Health Act
}

John Milton

From 1 April 1996 mental health legislation was expanded to include provision for "supervised discharge" under the Mental Health (Patients in the Community) Act 1995. However, the use of Section 17 (s17) of the Mental Health Act has always provided an option for an extended leave. This retrospective case note study examines 10 years of practice of $\$ 17$ use and focuses on characteristics of those patients recalled. increases in 817 applications represented equivalent increases in admisstons and overall sections, although numbers of patients actually recalled had fallen significantly. Patients recalled affer discharge were generally middle-aged men with a long history of schizophrenia, on s3, who relapse quickly due to treatment non-compliance.

Prior to the final introduction of the 1995 Mental Health (Patients in the Community) Act, the question of community supervision and treatment orders was widely debated in the Bulletin (Turner, 1994), within the Royal College of Psychiatrists, and within the Department of Health's own review of legal powers on mentally ill people in the community which preceded the Bill (Pease \& Reed, 1993). Many of the arguments recommending compulsory community treatment had been considered and rejected because of the prediction that compulsory treatment would contravene Article 5.1 of the European Convention of Human Rights. For example, simply stopping treatment without deterioration may not be seen as objective medical evidence of mental disorder sufficient for compulsory treatment. None the less, following the publication of the Royal College of Psychiatrists' report Community Supervision Orders (Royal College of Psychiatrists, 1993) suggesting expanded legislation for supervised discharge and extended leave, a survey of general psychiatrists was generally supportive of the changes (Hampson \& Davison, 1994).

In addition to the newer supervised discharge, leave of absence (s17, Mental Health Act, 1983) is that part of the Act already in use by which the responsible medical officer (RMO) formally grants leave outside the hospital, though the patient 
remains "liable to be detained". Patients are given a copy of guidelines, agreed before discharge, requiring compliance. In addition it allows patients' leave or discharge to be revoked 'when it is necessary in the interests of the patient's health or safety or for the protection of other people that he again becomes an inpatient", though the patient should be recalled to hospital should any treatment need to be administered.

The Hallstrom \& Gardner judgements (R. $v$. Hallstrom/Gardner, 20 December 1985, judgement of Mr Justice McCullough in the High Court of Justice, Queen's Bench Division, QB 1090 , Royal Courts of Justice) determined it to be illegal to recall a patient from leave specifically in order to ensure de facto extension of an order, though it is still possible to subject patients discharged from hospital to recall for up to six months. A retrospective controlled study of the use of 'extended leave' in community treatment found improved treatment compliance and reduced hospital admissions (Sensky et al, 1991).

Others have suggested that guardianship (s7, Mental Health Act) is underused, and with adequate cooperation of both mental health and social service teams, it can be used to ensure successful community supervision (Symonds, 1993). However, some see it as 'unenforceable' and a further argument against extra legislation for community treatment orders (Pierides \& Casey, 1993).

Although there are concerns that any attempt to introduce compulsory community treatment into English and Welsh mental health law would be a contravention of human rights, legally encouraged assertive community treatment continues to exist in both Jersey and Scotland. In Jersey, guardianship orders (Jersey Mental Health Act, 1969) allowing enforced treatment are used relatively frequently (Moate et al, 1993). while in Scotland compulsory community treatment still occurs as "extended leave of absence". which has not yet been successfully challenged in the Scottish courts (Chiswick, 1993).

Particularly given recent changes in the Act relating to "supervised discharge", it seemed likely to be useful to examine trends in recent practice of that part of the Act which already allows a degree of legally buttressed "supervision" once discharged.

This study aims first to examine the numbers and demography of patients recalled to hospital, and second to test the hypothesis that s17 (recall to hospital) after discharge had been increasingly used to assist in continuous community supervision of a group of patients who commonly default from treatment, the group for whom a community supervision order is often suggested.

\section{The study}

The study design was a retrospective case note descriptive review. All information was collected from Mental Health Act data held collectively by patient information services for two psychiatric provider units in Nottingham. Data were collected for the period 1 December 1983 (the onset of the 1983 Mental Health Act) until 1 December 1993, where available. Information on numbers of patient admissions and s2, s3 and s37 was available only from April 1987 when collection began. Section 17 for short leaves from hospital were excluded, and only s 17 used post-discharge was included in the study.

Basic information on all patients placed on $\mathrm{s} 17$ during the study period were collected from Mental Health Act records. Detailed information on those recalled including demographic details, diagnosis (specified at time of recall), section of Mental Health Act under which originally detained, number of years since index contact with psychiatric services, approximate number of previous admissions to hospital and length of time before recall was obtained from case notes for comparison with patients not recalled.

Data are presented descriptively and categorical data analysed with $\chi^{2}$ tests.

\section{Findings}

Use of $s 17$

Section 17 was applied 490 times over 10 years from 1983-1993, with reduced use in the mid1980 s but increasing application more recently. Sixty per cent of the sections were allowed to expire, $18.9 \%$ were formally discharged by the RMO and $2.0 \%$ were discharged by mental health review tribunal (MHRT). Sixty-seven episodes of recall (13.7\%) occurred for 61 patients after discharge.

Data collected on the use of s17 are expressed in terms of outcome i.e. section expired, regraded, recalled, discharged by MHRT, or other (died, represented voluntarily, section renewed) and presented in Table 1.

For the six years that total sections and admissions data are available (1987/8-1992/ $3)$, the proportion of sections converted to $\mathrm{s} 17$ has remained relatively stable despite overall increases of 22.1 and $23.9 \%$ for sections and admissions, respectively. However, only 4/309 (1.3\%) of 1993 total section patients were recalled compared to $9 / 253(3.6 \%)$ for 1988 total sections. Similarly there has been a significant reduction in the number of $s 17$ patients recalled in the five years $1988-1993(25 / 245)$ compared with years $1983-1988(42 / 245)\left(\chi^{2}=5.00\right.$, d.f. $=1$, $P<0.02$ ).

\section{Characteristics of recalled patients}

Of the 67 episodes of recall, 39 (58.2\%) were men. A greater proportion of patients were aged 
Table 1. Outcomes of Section 17 over 10 years

\begin{tabular}{|c|c|c|c|c|c|c|c|c|}
\hline $\begin{array}{l}\text { Date } \\
\text { discharge }\end{array}$ & $\begin{array}{l}\text { oftotal } \\
\text { admissions }\end{array}$ & $\begin{array}{l}\text { Total } \\
\text { sections } \\
(2,3,37)\end{array}$ & Tofal $\$ 17$ & $\begin{array}{l}\text { Expired/ } \\
\text { regraded }\end{array}$ & Discharged & Recalled & $\begin{array}{l}\text { Discharged } \\
\text { MHRT }\end{array}$ & Other \\
\hline $1983 / 4$ & - & - & 57 & 33 & 13 & 11 & 0 & 0 \\
\hline $1984 / 5$ & - & - & 57 & 38 & 8 & 9 & 0 & 2 \\
\hline $1985 / 6$ & - & - & 59 & 36 & 9 & 9 & 1 & 4 \\
\hline $1986 / 7$ & - & - & 35 & 27 & 3 & 4 & 1 & 0 \\
\hline $1987 / 8$ & 2282 & 253 & 37 & 22 & 5 & 0 & 0 & 1 \\
\hline $1988 / 9$ & 2724 & 249 & 44 & 24 & 7 & 9 & 2 & 2 \\
\hline $1989 / 90$ & 2613 & 207 & 47 & 35 & 7 & 4 & $\overline{1}$ & 0 \\
\hline $1990 / 1$ & 2547 & 301 & 46 & 25 & 10 & 5 & 1 & 5 \\
\hline $1991 / 2$ & 2729 & 325 & 50 & 23 & 16 & 3 & 1 & 7 \\
\hline $1992 / 3$ & 2827 & 309 & 58 & 32 & 15 & 4 & 3 & 4 \\
\hline
\end{tabular}

MHRT, mental health review tribunal.

over $35(55.2 \%)$ and $11.9 \%$ were aged over 60 . Patients recalled had a diagnosis of schizophrenia $52.2 \%, 11.9 \%$ bipolar affective disorder, $4.5 \%$ major depressive disorder and $11.9 \%$ miscellaneous diagnoses (e.g. drug-induced psychosis), although in $19.4 \%$ the diagnosis was not clearly stated. Although a majority of recalled patients had schizophrenia, this was significantly less than the number with schizophrenia who were not recalled $\left(\chi^{2}=9.22\right.$, d.f. $\left.=1, P>0.01\right)$.

Patients recalled were usually on $s 3(83.6 \%)$ or s37 (11.9\%) and more likely to have had at least five admissions, though this did not significantly differ from those not recalled. The mean length of psychiatric contact was 9.5 years for those patients recalled and although a history of either extensive contact with psychiatric services of at least 20 years $(26.9 \%)$ or after discharge from their first admission (17.9\%) was common, this did not differ significantly from the non-recalled patient group.

Sixteen patients $(23.9 \%)$ were recalled within a week of discharge, $35(54.7 \%)$ within a month, and by three months $52(81.3 \%)$ had been recalled. No patients were recalled within the final month of their section or had their section renewed. Reason for recall, although not formally studied, was almost universally linked to treatment non-compliance.

\section{Comment}

Clinicians may not be surprised that patients who were most likely to be recalled on $\mathrm{s} 17$ were middle-aged men with schizophrenia on s3, with a long psychiatric history including several admissions, who were recalled to hospital fairly quickly after discharge. What is surprising is that the group of patients recalled made up only one-seventh of total s17 use and were recalled with decreasing frequency despite increases in patient admissions, equivalent increases in compulsory admissions and proportionally more applications of $s 17$ overall.

This supports the view that $\mathbf{s} 17$ was not used as a community supervision order in the long term but, instead, reflected a 'trial' discharge in the community (albeit longer than leave from hospital), particularly for a group of patients who are recognised as having difficulties following previous admissions. Early recall, most within three months, seems to disprove the hypothesis that s17 was used to assist in continuous community surveillance.

The relative increase in use of $\mathrm{s} 17$ since $1987 / 8$ may reflect increased caution among clinicians facing discharge of challenging patients. The increase in active regrading rather than passive expiry of the section should be seen as the norm if collaboration rather than coercion is to be sought for future care. It is unclear from this study (which predates formal Care Programme Approach implementation locally) whether clear written guidelines for patients or the spectre of recall benefited them in maintaining good health. It is unlikely to be 'treatment' itself, such as antipsychotic drugs, that achieved this since s 17 does not allow community treatment to be administered.

The demographic features of patients recalled suggest a common recognition that a specific type of patient is more likely to relapse, to fail in treatment compliance but also to benefit from surveillance once discharged. This supports previous research suggesting non-compliance with treatment, rather than merely a diagnosis of schizophrenia, is a major factor influencing psychiatrists being asked to nominate patients for community treatment (Sensky et al, 1991).

What is not clear from this limited study is whether $s 17$ or early recall to hospital improves future care or prevents recurrence. It may be that those features that predict need for extra scrutiny can also be features of poorer prognosis 
or treatment resistance which may be improved by the subsequently introduced Care Programme Approach. Perhaps a prospective randomised trial of discharge with or without s17 would assist in confirming the reasons for a fall in the numbers of patients recalled.

\section{References}

CHiswick, D. (1993) Compulsory treatment in the community in Scotland: ten questions and answers. Psychiatric Bulletin, 17, 424-425.

HAMPSON. S. \& DAVISON, P. (1994) Proposed new legislation for the care of mentally ill people in the community. Psychiatric Bulletin, 18, 726-729.

MOATE, T., Ward, B. \& EVANS, G. (1993) A community treatment order in practice. Psychiatric Bulletin. 17. 585-586.
PEASE, R. D. B. \& REED, J. (1993) Legal Powers on the Care of Mentally II People in the Community: Report of the Internal Review. London: Department of Health.

Pierides. M. \& CASEY, C. (1993) A community treatment order (letter). Psychiatric Bulletin, 17, 300.

ROYAL COLLEG OF PSYCHIATRISTS (1993) Community Supervision Orders, Council Report CR18. London: Royal College of Psychiatrists.

SENSKY, T.. HuGhes, T. \& HIRSCH, S. (1991) Compulsory psychiatric treatment in the community. Parts I and II. British Journal of Psychiatry. 158, 792-799: 799-804.

SYMONDS, R. L. (1993) Guardianship - a case for wider use. Psychiatric Bulletin, 17, 276-278.

TURNER. T. (1994) Compulsory treatment in the community: some debating issues. Psychiatric Bulletin, 18. 657659.

John Milton, Senior Registrar, Nottingham Healthcare NHS Trust, Porchester Road, Nottingham NG3 6AA

\title{
Supervised discharge order: the first year in the South and West Region
}

\author{
Anna Knight, David Mumford and Bob Nichol
}

\begin{abstract}
Information was collected from responsible medical ofilicers (RMOS) in the South and West Region who hod used the new supervised discharge order (SDO) (Section 25a) during the first year of its operation. Twenty-nine patients were placed on a SDO by 19 consultants. Most patients suffered from schizophrenla. In a third of cases, modication was stipulated as a requirement, atthough this is not legally permiselble. RMOs commented on the time-consuming process of applying for a SDO and felt it had limitted value because of the lack of sanctions.
\end{abstract}

The Mental Health Act of 1983 is concerned exclusively with hospital-based assessment and treatment of patients suffering from psychiatric disorders. Since the Act, there has been a continuing shift in psychiatric practice towards community-based treatment, and this combined with the growing public concerns about a small number of highly publicised dangerous patients has been the impetus to further legislation.

On the 1 April 1996, the Mental Health (Patients in the Community) Act 1995 came into operation. The principal provision of this new Act was the supervised discharge order (SDO: Section 25a), which aims to ensure that patients discharged from Section 3 or Section 37 receive appropriate aftercare. A patient can be required to (a) live at a specified address, (b) allow access to the supervisor and other professionals and (c) to attend for specified treatment.

The aim of this project was to quantify the use of these new provisions in the South and West Region; determine the characteristics of patients placed on a SDO; and explore the experience of psychiatrists who have used the new powers in the first year. 